\title{
OCORRÊNCIA, DISTRIBUIÇÃO E TOXICIDADE DE CIANOBACTÉRIAS NO ESTUÁRIO DA LAGOA DOS PATOS, RS
}

\author{
MATTHIENSEN, A., ${ }^{1}$ YUNES, J. S. ${ }^{1}$ e CODD, G. A. ${ }^{2}$ \\ ${ }^{1}$ Unidade de Pesquisas em Cianobactérias, Departamento de Química, FURG, C.P. 474, \\ CEP 96201-900, Rio Grande, RS \\ ${ }^{2}$ University of Dundee, Department of Biological Sciences, DD14HN, Dundee, UK, e-mail: g.a.codd@dundee.ac.uk \\ Correspondência para: João Sarkis Yunes, Unidade de Pesquisas em Cianobactérias, Departamento de Química, \\ FURG, C.P. 474, CEP 96201-900, Rio Grande, RS, e-mail: dqmsarks@super.furg.br \\ Recebido em 23/12/97 - Aceito em 04/01/99 - Distribuído em 10/09/99
}

(Com 4 figuras)

\section{ABSTRACT \\ Occurrence, distribution and toxicity of cyanobacteria from the Patos Lagoon estuary, Southern Brazil}

Several blooms of Microcystis aeruginosa have been observed in the Patos Lagoon estuary during the last fifteen years without a proper investigation of their ecological importance or possible toxicity. The present study has identified and quantified the presence of cyanobacteria in the Patos Lagoon estuary, particularly of $M$. aeruginosa. During this survey, identification and quantification of the main phytoplankton groups were done in relation to geographical distribution in the estuary. The presence of $M$. aeruginosa colonies in the estuarine region confirmed their superficial distribution throughout the estuarine waters during twelve months with a maximum of $1,3.10^{6}$ cells. $\mathrm{L}^{-1}$ in December, 1994 and a minimum of $1,5.10^{5}$ cells. $\mathrm{L}^{-1}$ in August, 1995 and also confirmed that M. aeruginosa originated from waters in the north of the estuary. The period of the highest cell and colonies densities was coincident with high chlorophyll- $a$ levels in surface waters. Toxicity of $M$. aeruginosa bloom material was determined by bioassay and concentrations of hepatotoxins microcystins were identified by HPLC-DAD. M. aeruginosa blooms were considered highly toxic, presenting a $24 \mathrm{~h}-\mathrm{LD}_{50}$ lower than $100 \mathrm{mg} . \mathrm{Kg}^{-1}$ b.w. and a toxin content higher than $1 \mu \mathrm{g} \cdot \mathrm{mg}^{-1}$ d.w. Several microcystin variants were found in the extracts with microcystin-LR predominating.

Key words: cyanobacteria, Microcystis aeruginosa, hepatotoxins, Patos Lagoon estuary, microcystins.

\section{RESUMO}

Diversas florações da cianobactéria Microcystis aeruginosa têm sido observadas nas águas do estuário da Lagoa dos Patos nos últimos 15 anos, sem o devido estudo de sua distribuição e ocorrência ou do risco de contaminação do ecossistema aquático. Neste estudo, foram realizadas a identificação e a quantificação das cianobactérias da região estuarina da Lagoa dos Patos, particularmente $M$. aeruginosa, incluindo um levantamento quali-quantitativo dos principais grupos microfitoplanctônicos em relação à sua distribuição geográfica no estuário. Evidenciou-se que, ao longo de 12 meses, Microcystis aeruginosa esteve presente na região estuarina, com valor máximo de $1,3.10^{6}$ cél. $\mathrm{L}^{-1} \mathrm{em}$ dezembro de 1994 e mínimo de $1,5.10^{5}$ cél. $\mathrm{L}^{-1} \mathrm{em}$ agosto de 1995, evidenciando a região norte do estuário da Lagoa dos Patos como sua principal fonte de entrada. Os períodos de maior abundância celular e colonial dessa cianobactéria foram consistentes com os resultados obtidos para os níveis de clorofila- $a$ nas águas de superfície. Foram realizados testes de toxicidade $\left(\mathrm{DL}_{50}-24 \mathrm{~h}\right)$ em camundongos com os extratos das florações de $M$. aeruginosa e foram determinadas, através de HPLC-DAD, as concentrações e algumas das variantes da hepatotoxina microcistina. As florações de $M$. aeruginosa observadas foram consideradas altamente tóxicas, com concentrações celulares de toxinas atingindo valores maiores 
que $1 \mu \mathrm{g} \cdot \mathrm{mg}^{-1}$ p.s. e $\mathrm{DL}_{50}-24 \mathrm{~h}$ menores que $100 \mathrm{mg} \cdot \mathrm{Kg}^{-1}$ p.c. Encontraram-se diversas variantes da toxina microcistina, sendo microcistina-LR a principal.

Palavras-chave: cianobactéria, Microcystis aeruginosa, hepatotoxinas, estuário da Lagoa dos Patos, microcistinas.

\section{INTRODUÇÃO}

Florações algais são resultado da interação de fatores físicos, químicos e bióticos, caracterizadas por um crescimento explosivo, autolimitante e de curta duração dos microorganismos de uma ou poucas espécies, freqüentemente produzindo colorações visíveis nos corpos de águas naturais (Torgan, 1989). Os taxa Cyanophyta (cianobactérias), seguidos de Crysophyta, constituem os principais componentes das florações algais na Lagoa dos Patos, à semelhança do que ocorre em outras regiões do mundo (Torgan, 1989).

A ocorrência de florações de $M$. aeruginosa no estuário da Lagoa dos Patos é coincidente com ventos fracos ou ausentes, juntamente com temperatura da água acima de $20^{\circ} \mathrm{C}, \mathrm{pH}$ em torno de 8 , concentrações de nutrientes nitrogenados e de fósforo não-limitantes e relação N:P solúveis próxima a 13:1 (Yunes et al., 1996).

Dentre as espécies de cianobactérias produtoras de toxinas que formam florações estão: $A n a-$ baena flos-aquae, Microcystis aeruginosa, Aphanizomenon flos-aquae, Oscillatoria agardhii e Nodularia spumigena (Carmichael, 1989).

Microcystis aeruginosa é um dos organismos mais freqüentes entre as cianobactérias da comunidade fitoplanctônica do Guaíba, ao norte da Lagoa dos Patos (Amazarray, 1994). Em agosto de 1994, um cruzeiro realizado na região norte da Lagoa dos Patos revelou um depósito de Microcystis na Lagoa do Casamento $\left(30^{\circ} 21^{\prime} \mathrm{S}\right.$ e $50^{\circ} 44^{\prime} \mathrm{W}$ ), em uma camada $7 \mathrm{~cm}$ abaixo da superfície do sedimento, com as células sem atividades fisiológicas, evidenciando uma provável fonte para a próxima fase planctônica desses organismos (Yunes et al., 1994).

Ao contrário de outras cianobactérias (que produzem acinetos), as células de dormência de M. aeruginosa não são diferenciadas das células vegetativas, sendo capazes de sobreviverem por vários anos, à espera de períodos mais favoráveis ao seu desenvolvimento e reprodução (Paerl, 1988). Como possível conseqüência, muitas florações de
M. aeruginosa foram registradas na região estuarina da Lagoa dos Patos nos últimos 15 anos (Kantin \& Baumgarten, 1982; Bergesch, 1990; Odebrecht et al., 1987). Em fevereiro e maio de 1994, Yunes et al. (1994) observaram uma grande floração de Microcystis ao longo de todo o canal de navegação entre a cidade de Rio Grande e o Canal da Feitoria (cerca de 45 milhas náuticas), com níveis de clorofila- $a$ de até $9.000 \mu \mathrm{g} . \mathrm{L}^{-1}$. As amostras dessa floração, coletadas em diferentes locais da região estuarina, apresentaram toxicidade variável, sendo encontradas mais de duas variantes de microcistina (Yunes et al., 1996).

As hepatotoxinas de cianobactérias são moléculas cíclicas com 5 ou 7 peptídeos, de baixo peso molecular, chamadas nodularinas ou microcistinas. Animais com hepatotoxicose são levados à morte após alteração citoesquelética das células do fígado, causando hemorragia intra-hepática letal ou insuficiência hepática. A hepatotoxina mais comum é a microcistina $\left(\mathrm{MC}\right.$, com $\mathrm{DL}_{50}-24 \mathrm{~h}$ entre 43 e $250 \mathrm{mg} . \mathrm{Kg}^{-1}$ de p.c.) (Volterra, 1993). Em nível molecular, as microcistinas agem como inibidores das proteínas fosfatase 1 (PP1) e 2A (PP2A) (MacKintosh et al., 1990). Portanto, sua exposição a doses subletais pode contribuir, a longo prazo, para o desenvolvimento de tumores cancerígenos (Fujiki, 1992; MacKintosh \& MacKintosh, 1994).

Vários problemas de saúde humana, após o contato com águas com cianobactérias em floração, foram reportados mundialmente, em atividades recreacionais ou pelo consumo de águas de reservatórios contaminadas (Elder et al., 1993; Codd et al., 1989; Carmichael, 1986). Em abril de 1996, foi detectada a presença da toxina MC-LR no Açude Tabocas, em Caruaru, PE, o qual fornecia água ao reservatório do Instituto de Doenças Renais (IDR) desta cidade, e em amostras de fígado e sangue de pacientes de hemodiálise deste Instituto. Foram também encontradas altas doses no filtro de carvão ativado que purificava a água usada pelo IDR (Azevedo, 1996). Até o presente momento, mais de 40 pacientes morreram de hepatite tóxica (Barreto et al., 1996). Outras ocorrências 
de florações tóxicas, no Brasil, foram comprovadas, através de bioensaios, em reservatórios de água do Rio de Janeiro (Aguiar \& Azevedo, 1993; Bobeda \& Azevedo, 1993; Azevedo et al., 1994) e em São Paulo (Zagatto \& Aragão, 1992; Zagatto, 1995).

A Lagoa dos Patos compreende uma área aproximada de $200.000 \mathrm{Km}^{2}$ de bacia de drenagem. Ao longo de suas margens, mais de 3.000 .000 de habitantes vivem em cidades, vilas e povoados, utilizando as águas da lagoa para pesca, agricultura, indústria, navegação, consumo doméstico e lazer (Yunes et al., 1994). A região estuarina (Fig. 1) representa, aproximadamente, um décimo da área total da Lagoa dos Patos (Castello, 1978) e está definida entre o Canal da Barra de Rio Grande e a Feitoria. O estuário da Lagoa dos Patos está sujeito a grandes variações de salinidade, temperatura e de nutrientes. Segundo Calliari (1980), suas águas podem apresentar variações de salinidade de até 20 unidades num período de $1 \mathrm{~h}$, ocorrendo, também, situações de grande homogeneidade. As maiores salinidades são observadas no verão, com menores valores na primavera e outono (Kantin \& Baumgarten, 1982). Variações de temperatura de até $15^{\circ} \mathrm{C}$ também ocorrem em curto espaço de tempo e acompanham as variações sazonais (Kantin \& Baumgarten, 1982). A entrada de nutrientes na região estuarina ocorre, principalmente, através da drenagem continental.

Aproximadamente $85 \%$ do total de água doce que entra no sistema provém dos rios tributários localizados na parte superior da Lagoa dos Patos (Niencheski \& Windom, 1994). Dentro do estuário, as concentrações dos nutrientes provenientes do Canal de São Gonçalo são resultado, principalmente, de atividades agriculturais da bacia hidrográfica da Lagoa Mirim. As águas de superfície, próximas à desembocadura do estuário, apresentam grandes concentrações de nutrientes, provavelmente devido à contaminação por esgotos domésticos e à descarga atmosférica local do parque industrial da cidade de Rio Grande (Niencheski et al., 1994). O estuário da Lagoa dos Patos é considerado uma área de alta produção primária (Kantin \& Baumgarten, 1982), em que a ação dos ventos e a advecção de diferentes massas de água são os principais fatores determinantes da distribuição espacial e temporal do fitoplâncton (Odebrecht et al., 1988). A intensidade dos ventos e a sua direção também determinam os fluxos de marés enchentes e vazantes em relação à saída ao Oceano Atlântico. As amplitudes de maré na região estuarina são pequenas (aproximadamente $0,47 \mathrm{~m}$ ) (Proença, 1990), porém, em condições em que os ventos não interferem, as taxas de descarga no estuário são condicionados pelas marés (Mata \& Möller, 1993).

O presente trabalho teve por objetivos avaliar a ocorrência e a distribuição das florações de cianobactérias, ao longo de um ano, no estuário da Lagoa dos Patos, além de caracterizar e quantificar as toxinas encontradas nas células em floração e livres na água.

Ainda, buscou-se identificar as principais classes e estimar os valores de abundância do microplâncton que ocorre nos períodos que antecedem, sucedem e acompanham uma floração de cianobactérias e, assim, obter uma melhor compreensão do estuário como um sistema dinâmico.

\section{MATERIAL E MÉTODOS}

\section{Coletas}

Os locais de coleta das amostras estenderamse por 6 estações fixas dentro do estuário da Lagoa dos Patos: 2 estações em áreas de baixa profundidade - estação Marambaia (32 $02^{\circ} 15^{\prime \prime} \mathrm{S}$ e $\left.52^{\circ} 05^{\prime} 30^{\prime \prime} \mathrm{W}\right)$ e estação Torotama ( $31^{\circ} 55^{\prime} 00^{\prime \prime} \mathrm{S}$ e $\left.52^{\circ} 09^{\prime} 00^{\circ} \mathrm{W}\right)$; uma estação no Canal de São Gonçalo ( $31^{\circ} 47^{\prime} 19^{\prime \prime}$ 'S e $\left.052^{\circ} 13^{\prime} 30^{\prime \prime} \mathrm{W}\right)$; e três estações situadas no canal de navegação, sendo uma em frente à Praia do Laranjal (estação Farolete, $31^{\circ} 44^{\prime} 25^{\prime \prime}$ 'S e $52^{\circ} 06^{\prime} 05^{\prime \prime} \mathrm{W}$ ), uma na Ponta da Feitoria (estação Feitoria, $31^{\circ} 43^{\prime} 24^{\prime \prime}$ 'S e $52^{\circ} 00^{\prime} 12^{\prime \prime} \mathrm{W}$ ) e outra próxima à desembocadura da Barra do Rio Grande (estação Barra, $32^{\circ} 08^{\prime} 02^{\prime \prime}$ S e 52 $05^{\prime} 51^{\prime \prime} \mathrm{W}$ ) (Fig. 1).

Os cruzeiros foram realizados com a lancha Larus, da Universidade do Rio Grande, tendo periodicidade mensal e duração de 2 dias. As amostragens foram complementadas com coletas ocasionais, em função da presença de florações de cianobactérias na região estuarina da Lagoa dos Patos: Yacht Club (32 $2^{\circ} 02^{\prime} \mathrm{S}$ e $\left.52^{\circ} 07^{\prime} \mathrm{W}\right)$ e Nascimento Norte $\left(31^{\circ} 45^{\prime} \mathrm{S}\right.$ e $\left.52^{\circ} 06^{\prime} \mathrm{W}\right)$, e na Praia do Cassino ( $32^{\circ} 11^{\prime} \mathrm{S}$ e $\left.52^{\circ} 09^{\prime} \mathrm{W}\right)$.

\section{Biomassa}

A biomassa do fitoplâncton foi determinada mediante análise de clorofila- $a$, na Unidade de Pesquisa em Cianobactérias da Universidade do 
Rio Grande. O teor de clorofila- $a$ dos extratos metanólicos das amostras foi determinado a $663 \mathrm{~nm}$ em espectrofotômetro e calculado segundo o coeficiente de Mackinney (1941).

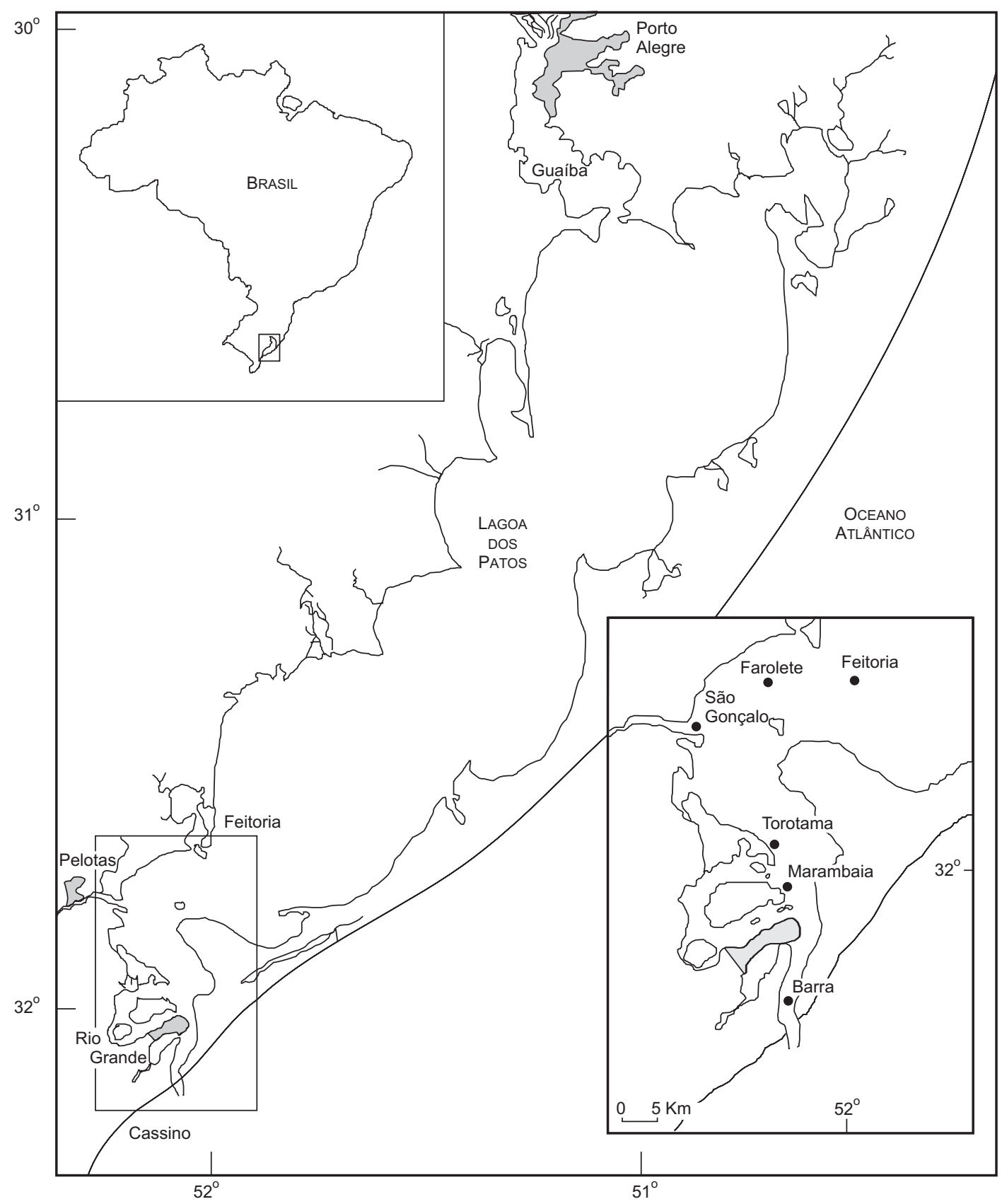

Fig. 1 - Mapa da Lagoa dos Patos (RS) e região estuarina com os respectivos locais de amostragem. 


\section{Levantamento quali-quantitativo do microplâncton}

Para a identificação e a quantificação da comunidade microplanctônica, volumes de amostras de $100 \mathrm{ml}$ foram fixados (1:100 ml) em solução de Lugol. A determinação da composição microplanctônica foi realizada mediante a concentração do material por sedimentação, em volumes de 2 a $10 \mathrm{ml}$, em câmaras de Utermöhl (Utermöhl, 1958) e contagem em microscópio invertido. A identificação do microplâncton realizou-se em nível de classes (segundo Desikachary, 1959; Dodge, 1985; Maeda \& Carey, 1985; Priddle \& Fryxell, 1985; Komárek \& Anagnostidis, 1986; Sournia, 1986; Ricard, 1987; Anagnostidis \& Komárek, 1988; Balech, 1988; Komárek \& Anagnostidis, 1989).

\section{Quantificação de Microcystis aeruginosa}

Foi realizado um experimento seletivo para a quantificação das células de Microcystis aeruginosa. As amostras de água coletadas da superfície e conservadas em solução de Lugol, das estações Feitoria, Torotama e Barra, foram submetidas a digestão a quente $\left(90^{\circ} \mathrm{C}\right) \mathrm{com} \mathrm{NaOH}$, solução final 0,01 M (Reynolds \& Jaworski, 1978; Box, 1981) por $90 \mathrm{~min}$. Após a digestão, foi realizada a contagem em Câmara de SedgewickRafter, através de microscopia ótica, no aumento de $200 \mathrm{x}$, e um total de 35 a 40 campos.

\section{Testes de toxicidade com camundongos}

Material algáceo foi coletado de duas maneiras diferentes para os testes de toxicidade. Nas estações ocasionais (não-fixas) - Yacht Club Rio Grande e Praia do Cassino, em dezembro de 1994, e Nascimento Norte, em janeiro de 1995 -, as amostras da floração foram coletadas por meio de balde, e mantidas em sacos plásticos a $5^{\circ} \mathrm{C}$. Nas estações fixas (Farolete, Feitoria, Marambaia e Barra, todas em dezembro de 1994), as amostras da floração foram concentradas por meio de arrasto com rede fitoplanctônica (144 $\mu \mathrm{m}$ de malha), durante três minutos, à velocidade de 3 milhas. ${ }^{-1}$. Essas amostras foram congeladas e, posteriormente, liofilizadas.

O material liofilizado foi pesado em balança analítica e dividido em, no mínimo, 6 concentrações de extrato algáceo, preparadas em solução fisiológica 9g. $\mathrm{L}^{-1} \mathrm{NaCl}$, seguindo, inicialmente, a dupla diluição entre 0 e $1.000 \mathrm{mg} \cdot \mathrm{Kg}^{-1}$ de peso corporal (p.c.) do camundongo. Posteriormente, as dosagens variaram entre 15 e $100 \mathrm{mg} . \mathrm{Kg}^{-1}$ p.c., para se obter maior precisão da dose letal média em $24 \mathrm{~h}\left(\mathrm{DL}_{50}-24 \mathrm{~h}\right)$.

Foram utilizados 5 camundongos machos "Swiss-albinos" para cada dose (peso médio: 22,5 g), e os extratos foram aplicados intraperitonialmente, no volume de $10 \mu \mathrm{l} . \mathrm{g}^{-1}$ de peso dos camundongos. Os controles foram realizados com a aplicação de solução fisiológica e uma amostra de cianobactéria não-tóxica (Aphanotece microscopica RSMan9201, Coleção de Culturas da UPC, Universidade do Rio Grande) na mais alta dosagem. O cálculo da $\mathrm{DL}_{50}-$ $24 \mathrm{~h}$ foi obtido pelo método estatístico de SpearmanKarber, com intervalo de confiança de 95\% (Hamilton et al., 1977). Camundongos moribundos e comportamentos anormais não foram considerados como parâmetros de mortalidade.

\section{Análises quali-quantitativas das toxinas}

Em cada estação (fixa e não-fixa), 1 litro de água superficial foi filtrado (filtros GF/C $70 \mathrm{~mm}$ ), em bomba de vácuo com pressão inferior a $20 \mathrm{~mm}$ de mercúrio. Os filtros foram, então, liofilizados durante 24 horas e extraídos em $25 \mathrm{ml}$ de metanol absoluto, durante 1 hora, à temperatura ambiente. Após o tempo decorrido, o extrato metanólico foi separado e essa operação foi repetida. Terminada a segunda extração, juntaram-se os 2 extratos, e o metanol foi evaporado a $40^{\circ} \mathrm{C}$ a vácuo, em evaporador rotatório. $\mathrm{O}$ resíduo foi solubilizado em 5 volumes de $200 \mu \mathrm{l}$ de metanol, resultando em $1 \mathrm{ml}$ de metanol contendo as toxinas. $\mathrm{O}$ volume final foi, então, estocado a $-20^{\circ} \mathrm{C}$ para a análise de HPLC-DAD, utilizando-se, como padrão, uma amostra pura de MC-LR.

Para a análise das toxinas livres na água, 1 litro de água superficial foi coletado nas estações nãofixas e filtrados (GF/C $70 \mathrm{~mm})$ em bomba de vácuo. Cada amostra foi dividida em 2 subamostras de 500 $\mathrm{ml}$ e a uma delas foram adicionados $150 \mu \mathrm{l}$ de solução de MC-LR pura contendo $5 \mu \mathrm{g}$ da toxina, a qual foi utilizada como padrão. Em ambas as subamostras foram adicionados $5 \mathrm{ml}$ de Ácido Trifluoroacético (TFA) $10 \%$, agitados e filtrados novamente em GF/ C. A extração de fase sólida foi realizada em uma estação de vácuo (Vac Elut SPS-24, Varian Analytical Instruments, CA, USA), acoplada a colunas de retenção $\mathrm{C}_{18}$ Isolute $1 \mathrm{~g} / 3 \mathrm{ml}$ (Millipore, USA). As colunas de retenção foram ativadas com $10 \mathrm{ml}$ de metanol absoluto seguidos de $10 \mathrm{ml}$ de água Milli-Q (Millipore, MA, USA) com fluxo de $10 \mathrm{ml} \cdot \mathrm{min}^{-1}$. As 
subamostras foram, então, passadas através das colunas de retenção e estas foram secas com a passagem de ar durante $30 \mathrm{~min}$. A extração das toxinas foi realizada passando-se $3 \mathrm{ml}$ de metanol acidificado (metanol: TFA $0,1 \%, \mathrm{v} / \mathrm{v}$ ) pelas colunas. Os extratos coletados foram secos por borbulhamento com nitrogênio a quente (45rC) e ressuspensos em $100 \mu 1$ de metanol. As amostras foram centrifugadas e o sobrenadante foi analisado em HPLC-DAD.

A análise em HPLC-DAD foi executada em aparelho Waters (Chromatography Division, Millipore Corp., USA) e um auto-amostrador 717 WISP. A detecção foi realizada por meio de um Detector de Foto-Diodo 991, entre 200 e $300 \mathrm{~nm}$ de comprimento de onda, com $3 \mathrm{~nm}$ de resolução. Uma coluna Waters $\mu$ Boundpack $\mathrm{C}_{18} 3,9 / 300 \mathrm{~mm}$ (Millipore Corp., USA), foi utilizada para todos os procedimentos analíticos. Volumes de $100 \mu 1$ de extrato metanólico das amostras foram colocados no auto-amostrador e $25 \mu 1$ foram injetados na coluna. A separação foi realizada com um gradiente linear (água:acetonitrila) de $70 \%$ de água e $30 \%$ de acetonitrila, e trocado, gradualmente, para $100 \%$ de acetonitrila após $40 \mathrm{~min}$.

\section{RESULTADOS}

\section{Variação sazonal do microplâncton no estuário}

A variação sazonal da clorofila- $a(\mathrm{cl}-a)$ nos 12 meses estudados (Fig. 2) apresentou, na maioria das estações, um padrão anual abaixo dos $10 \mu \mathrm{g} \cdot \mathrm{L}^{-1}$. Em determinadas épocas, predominantemente no verão, os valores foram superiores, ocorrendo um aumento das concentrações de clorofila- $a$ em função de uma maior biomassa fitoplanctônica em todo o estuário. Picos ocorreram em fevereiro de 1995, atingindo valores de até $25 \mu \mathrm{g} . \mathrm{L}^{-1}$, em algumas estações do estuário. $\mathrm{O}$ pico observado em setembro de 1994, na estação Farolete, atingiu $29 \mu \mathrm{g} . \mathrm{L}^{-1}$. Esse pico é atípico e é resultado da ação de fortes ventos de NE na região. As médias dos valores de clorofila$a$ para o estuário (excluindo-se a estação São Gonçalo) no inverno e na primavera são semelhantes, com 7,23 $\mu \mathrm{g} . \mathrm{L}^{-1}$ e $7,27 \mu \mathrm{g} . \mathrm{L}^{-1}$, respectivamente, e o outono apresentou os mais baixos valores, com média de $2,14 \mu \mathrm{g} . \mathrm{L}^{-1}$. No verão, o valor médio de clorofila- $a$ para o estuário ficou em torno de 13 $\mu \mathrm{g} . \mathrm{L}^{-1}$.

A abundância do microplâncton durante os 12 meses estudados, no estuário da Lagoa dos Pa- tos, foi dividida em 5 grupos (bacillariophyceae, chlorophyceae, cyanophyceae, dinophyceae e ciliata), e um grupo denominado "outros" (o restante do microplâncton), e plotada em função de suas localizações geográficas (Fig. 3).

O grupo bacillariophyceae apresentou as maiores concentrações, alcançando valores próximos a $1.10^{6}$ cél. $\mathrm{L}^{-1}$, no mês de janeiro de 1995 , nas estações ao norte do estuário (Farolete e Feitoria) (Fig. 3a). Outras concentrações elevadas $\left(\oplus 3.10^{5}\right.$ cél. $\left.\mathrm{L}^{-1}\right)$ foram observadas nas estações Torotama (em dezembro de 1994) e São Gonçalo (em fevereiro de 1995).

O grupo chlorophyceae teve concentração mais elevada no Canal de São Gonçalo (Fig. 3b), composto, particularmente, por espécies predominantes em água doce. Entretanto, a maior concentração observada desse grupo (em outubro de 1994) não ultrapassou o valor de $1,5.10^{5}$ cél. $\mathrm{L}^{-1}$.

Por questões metodológicas, o grupo cyanophyceae foi quantificado em colônias. $\mathrm{L}^{-1}$ e tricomas. $L^{-1}$ (Fig. 3c). A maior concentração observada, em fevereiro de 1995, na estação São Gonçalo foi composta de Anabaena spiroides, a qual atingiu valores de $3,3.10^{5}$ e de $1,2.10^{4}$ tricomas. $\mathrm{L}^{-1}$, em agosto de 1994, na estação Feitoria. Nesta estação, esta espécie continuou aparecendo, porém em menor quantidade, no mês seguinte e também em dezembro de 1994. Nesse mês, na estação Farolete, as cianobactérias apresentaram grandes concentrações de colônias, sendo este o único mês em que foi encontrada, nessa estação, a espécie $A$. spiroides. Os demais valores correspondem, principalmente, a colônias de Microcystis aeruginosa, as quais mostraram um aumento significativo em suas concentrações no mês de dezembro de $1994 \mathrm{em}$ quase todas as estações, com maior valor na estação Barra (9.000 colônias. $\left.\mathrm{L}^{-1}\right)$. Na Feitoria, as colônias de Microcystis aeruginosa em dezembro ficaram em torno de 6.000 colônias. $L^{-1}$, enquanto na estação Farolete, os valores mais elevados de $M$. aeruginosa foram encontrados em janeiro (5.250 colônias. $\mathrm{L}^{-1}$ ).

O grupo dinophyceae teve seu pico máximo na estação Barra, durante os meses de janeiro e fevereiro de 1995 (Fig. 3d), com um acompanhamento deste aumento, em fevereiro, nas estações Marambaia e Torotama.

Essas 3 estações têm, como característica em comum, a maior proximidade com a desembocadura do estuário, tanto que, em junho de 1995, foi 


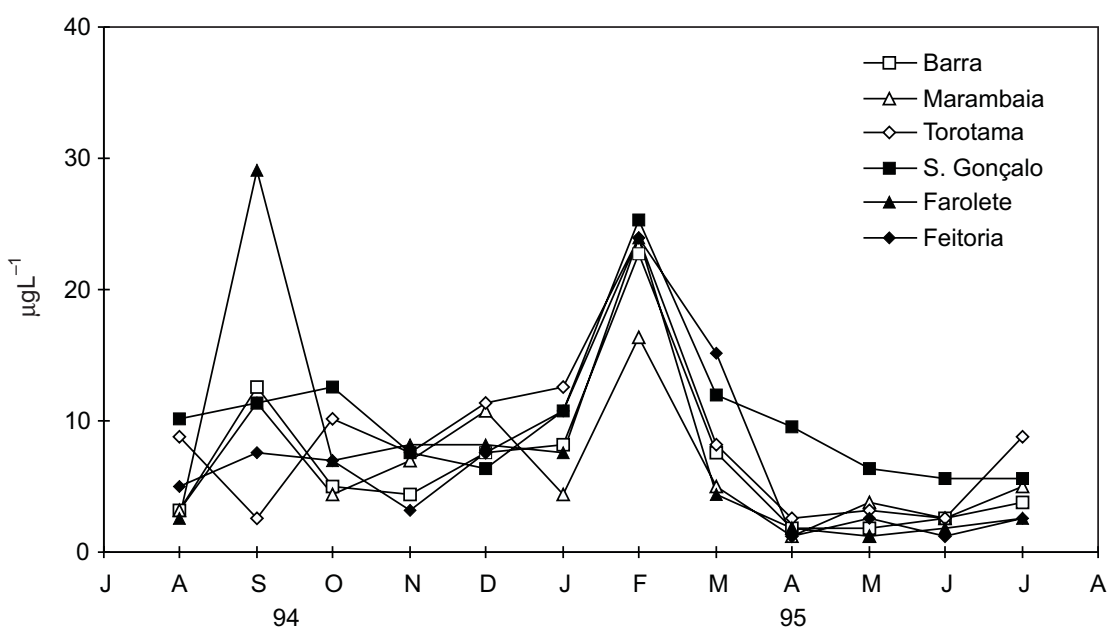

Fig. 2 - Variação sazonal das concentrações de clorofila- $a$ nas seis estações do estuário da Lagoa dos Patos (RS), durante 12 meses.

observado um novo aumento na concentração de dinoflagelados na estação Barra.

O grupo ciliata apresentou concentrações baixas durante praticamente o ano todo (Fig. 3e). Esse grupo foi separado do grupo denominado "outros" pela presença, durante o outono de 1995, do ciliado autotrófico Mesodinium rubrum, o qual atingiu concentração máxima em junho de 1995 na estação Farolete (13.500 cél.L $\left.{ }^{-1}\right)$.

O grupo "outros" compreendeu espécies de chrisophyceae, euglenophyceae, raphydophyceae e demais microplânctons, os quais não foi possível a identificação, em baixas concentrações (Fig. 3f). Nessa categoria também foram incluídos as formas cistônicas e grânulos de amido. A variação total desse grupo oscilou de 27.200 a menos de 1.000 cél. $L^{-1}$.

\section{Variação geográfica do microplâncton no estuário}

Analisando por estações, a Estação Barra, apesar de situar-se em zona de maior profundidade e estar na desembocadura oceânica, apresentou semelhança, na predominância dos grupos microplanctônicos, às estações Marambaia e Torotama.

$\mathrm{Na}$ estação Marambaia houve predominância de bacilariofíceas durante quase todo o ano (de setembro a julho). No mês de dezembro, 2 gêneros tiveram altos valores: Melosira $\left(92.400\right.$ cél. $\left.\mathrm{L}^{-1}\right)$ e Skeletonema $\left(58.600\right.$ cél. $\left.\mathrm{L}^{-1}\right)$. Isto indica uma possível troca de dominância entre estes 2 gêneros, pois, no mês seguinte, Skeletonema compreendeu $87 \%$ das diatomáceas. Em fevereiro de 1995, as maiores concentrações foram de Skeletonema, Asterionelopsis e Coscinodiscus. Na estação Torotama, o maior pico de diatomáceas, em dezembro de 1994, foi constituído, basicamente, por Melosira sp. Os valores elevados de janeiro, fevereiro e abril de 1995 também compreenderam o gênero Skeletonema. Em geral, as diatomáceas predominaram de novembro a fevereiro, além de abril, maio e julho.

A estação São Gonçalo, um canal de contribuição de água doce ao estuário, apresentouse de forma bastante heterogênea das demais. Houve alternância de predominância do fitoplâncton entre clorofíceas, em que se destacaram os gêneros Planktonema e Scenedesmus, e entre diatomáceas, com pico em fevereiro (362.800 cél. $\mathrm{L}^{-1}$ ), e, ainda, em maio e julho, com predominância do gênero Melosira em todos os meses. As cianobactérias da estação São Gonçalo foram mais abundantes em fevereiro, com 337.900 tricomas. $\mathrm{L}^{-1}$ de A. spiroides. Foi observada uma maior concentração de células de M. aeruginosa no período correspondente ao verão, com pico máximo no mês de dezembro. Ainda, evidenciou-se um pequeno aumento na concentração de Microcystis, nos meses de setembro de 1994 e julho de 1995.

Nas estações mais ao Norte no estuário, Farolete e Feitoria, registrou-se uma tendência de aumento fiotoplanctônico durante os meses de verão, 

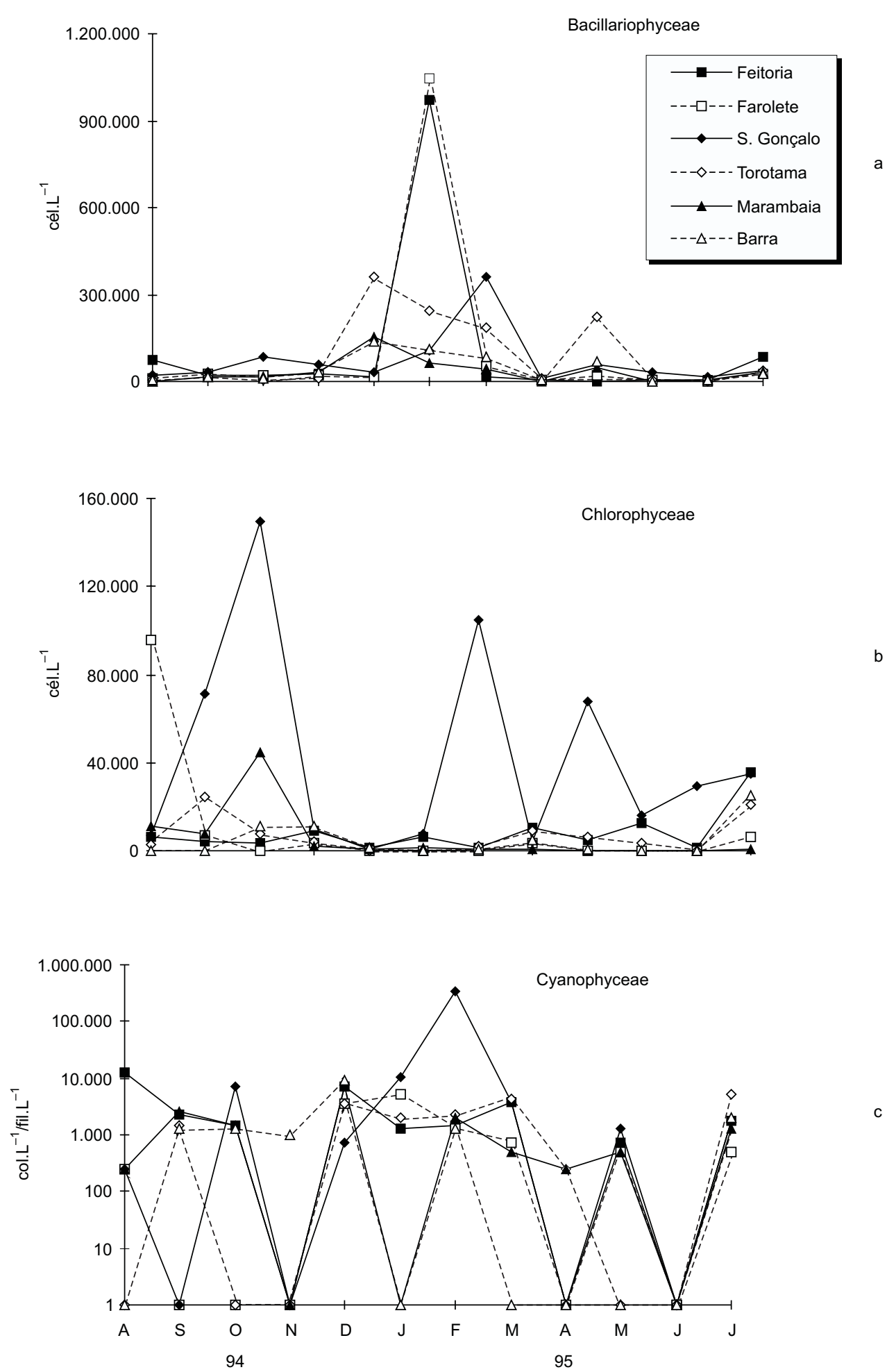

Fig. 3 - Abundância dos principais grupos microfitoplanctônicos nas seis estações do estuário da Lagoa dos Patos (RS), durante 12 meses: (a) bacillariophyceae; (b) chlorophyceae; (c) cyanophyceae. 

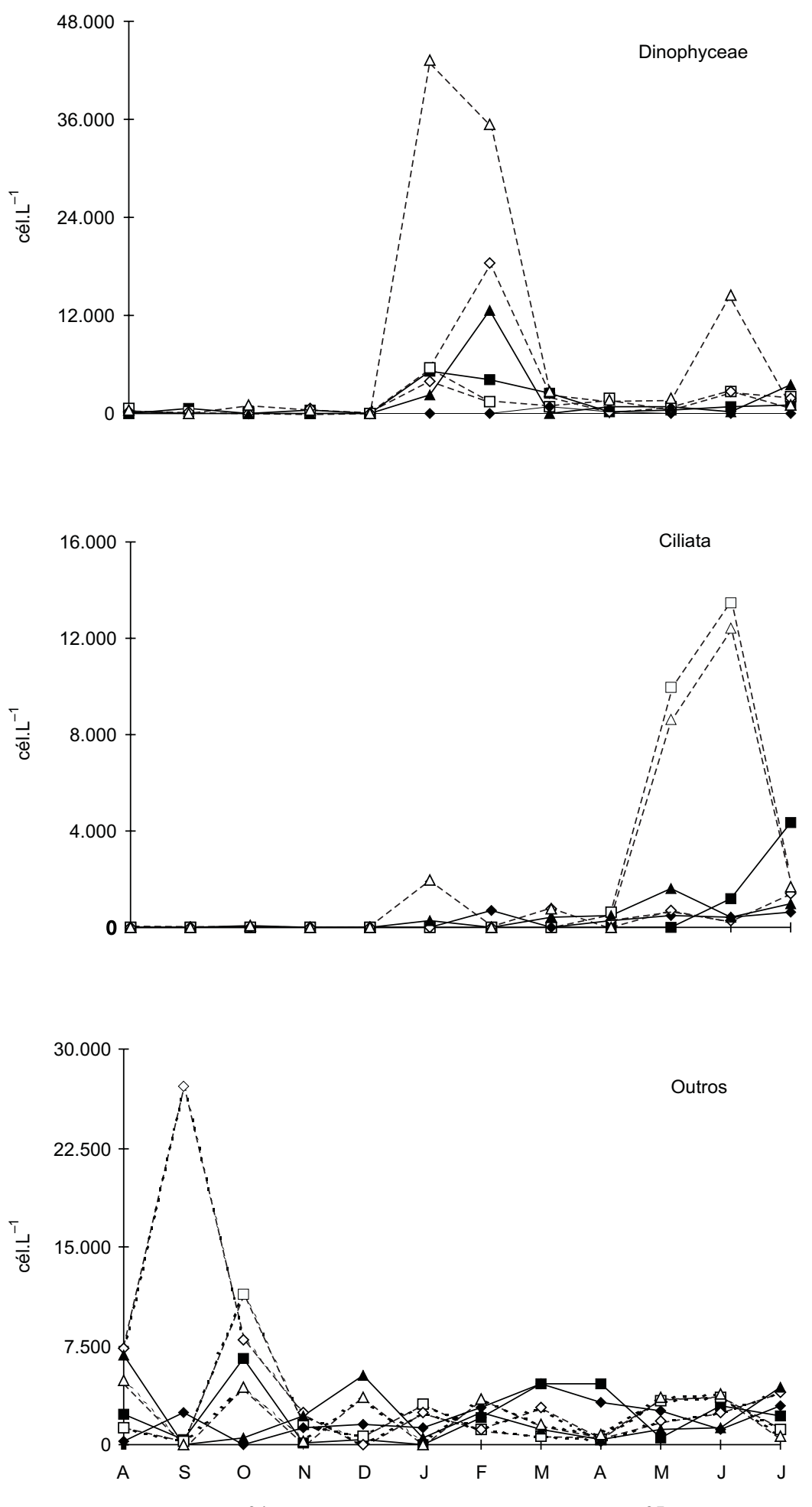

94

95

Fig. 3 - Abundância dos principais grupos microfitoplanctônicos nas seis estações do estuário da Lagoa dos Patos (RS), durante 12 meses: (d) dinophyceae; (e) ciliata; e (f) outros. 
com destaque para o grupo bacillariophyceae $\left(>9,0.10^{6}\right.$ cél. $\left.\mathrm{L}^{-1}\right)$ e menor evidência para o grupo dynophyceae $\left(<10.000\right.$ cél. $\left.\mathrm{L}^{-1}\right)$, enquanto outros grupos (Fig. 3f) foram ressuspensos durante os fortes ventos de outubro de 1994.

\section{Ocorrência de Microcystis aeruginosa}

A Fig. 4 mostra a estimativa da distribuição da abundância de $M$. aeruginosa, quantificada em câmara de Sedgewick-Rafter, em 3 estações (Feitoria, Torotama e Barra) ao longo dos 12 meses, em que se evidencia que essa espécie esteve sempre presente na região estuarina, mesmo em concentrações reduzidas.

Os meses de maior concentração celular de M. aeruginosa foram entre dezembro de $1994 \mathrm{e}$ março de 1995 (entre 0,5 e 1,5.10 cél.L $^{-1}$ ), mostrando a mesma tendência anual da variação da clorofila- $a$ no estuário da Lagoa dos Patos, RS.

\section{Toxicidade das florações e toxinas no estuário}

Os dados de concentração de toxinas e toxicidade nas estações de coleta são apresentados na Tabela 1. Durante a floração de dezembro de 1994, nas estações Feitoria, Farolete, Marambaia e Barra, foi observado um pequeno gradiente nas concentrações das toxinas totais das células de $M$. aeruginosa, assim como na biomassa das florações (clorofila- $a$ ). A estação Feitoria apresentou menores valores de clorofila- $a\left(7,57 \mu \mathrm{g} . \mathrm{L}^{-1}\right)$ e menores valores de toxinas $\left(0,161 \mu \mathrm{g} \cdot \mathrm{mg}^{-1}\right)$. No outro extremo, a estação Barra teve o mais alto valor de clorofila- $a\left(41,0 \mu \mathrm{g} \cdot \mathrm{L}^{-1}\right)$ e a maior concentração de toxinas nas células $\left(1,121 \mu \mathrm{g} \cdot \mathrm{mg}^{-1}\right)$. Quanto à variedade das microcistinas encontradas, uma variante (possivelmente MC-FR) predominou nas amostras da estação Farolete e compôs metade do total de toxinas na estação Marambaia, ocorrendo em menor quantidade na estação Barra. Já a variante MC-LR compôs a outra metade das toxinas da estação Marambaia e, aproximadamente, um quarto das toxinas da estação Barra, sendo que as demais variantes apresentaram tempos de retenção maiores (dados não apresentados).

Outros valores de toxicidade nas células de $M$. aeruginosa durante essa floração também foram obtidos para amostras da Praia do Cassino, Yacht Club e Nascimento Norte. Nas coletas realizadas na Praia do Cassino, valores médios de 76,2 $\mu \mathrm{g} . \mathrm{L}^{-1}$ de clorofila- $a$ e concentrações de $4,55 \mu \mathrm{g}$ de toxinas por litro de filtração foram encontrados, compreendendo, exclusivamente, uma variante (possivelmente MC-FR), enquanto a concentração de toxinas livres na água foi de $0,65 \mu \mathrm{g} . \mathrm{L}^{-1}$.

As amostras do Nascimento Norte atingiram, em média, $4.786 \mu \mathrm{g} . \mathrm{L}^{-1}$ de clorofila- $a$, com a concentração de microcistinas na água desse local, em janeiro de 1995 , de $244,8 \mu \mathrm{g} . \mathrm{L}^{-1}$ e a concentração de toxinas nas células de $0,276 \mu$ g. $\mathrm{mg}^{-1}$ p.s., separadas em 4,3\% de MC-LR e 95,7\% da possível variante MC-FR.

A floração coletada nas águas do Yacht Club de Rio Grande possuía valores de clorofila- $a$ de $1.066,9 \mu \mathrm{g} . \mathrm{L}^{-1}$, a qual apresentou uma concentração

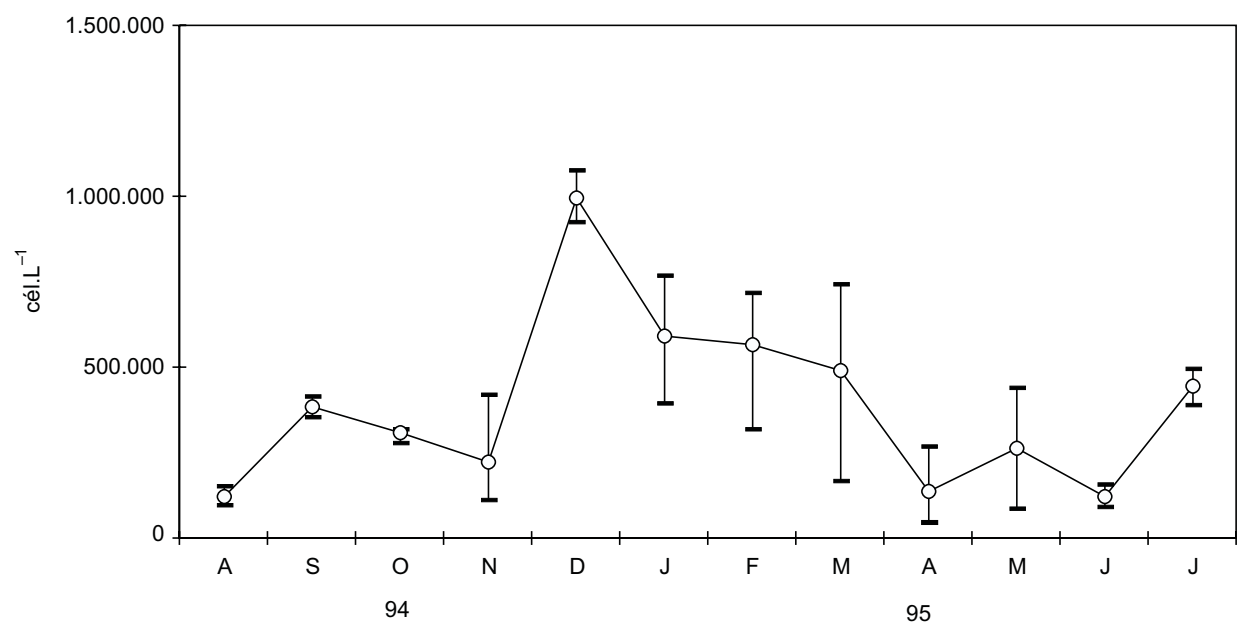

Fig. 4 - Média da distribuição de Microcystis aeruginosa ao longo de 12 meses, quantificado em Câmara de SedgewickRafter, nas estações Feitoria, Torotama e Barra. 


\section{TABELA 1}

Concentração de toxinas nas células, toxicidade (95\% de intervalo de confiança) e biomassa de Microcystis aeruginosa, e seus métodos de coleta, em diferentes estações no estuário da Lagoa dos Patos, RS. Análises de M. aeruginosa PCC7813 e Aphanothece microscopica RSMan9201 foram utilizados para comparação e controle, respectivamente.

\begin{tabular}{|c|c|c|c|c|c|c|c|c|}
\hline $\begin{array}{l}\text { Local de } \\
\text { amostragem }\end{array}$ & Data & $\begin{array}{c}\text { Método de } \\
\text { coleta }\end{array}$ & $\begin{array}{c}\text { Clorofila- } a \\
\left(\mu \mathrm{g} . \mathrm{L}^{-1}\right)\end{array}$ & $\begin{array}{r}\text { MC - LR } \\
\left(\mu \mathbf{g . m g}^{-1}\right)\end{array}$ & $\begin{array}{c}* * \mathbf{M C}-\mathbf{F R} \\
\left(\mu \mathrm{g} \cdot \mathrm{mg}^{-1}\right)\end{array}$ & $\begin{array}{c}\text { MC - Total } \\
\left(\mu \mathrm{g} \cdot \mathrm{mg}^{-1}\right)\end{array}$ & $\begin{array}{c}\text { MC - total } \\
\text { na água } \\
\left(\mu_{\mathrm{g} . L^{-1}}\right)\end{array}$ & $\begin{array}{l}\mathrm{DL}_{50} 24 \mathrm{~h} \\
\left(\mu \mathrm{gg} \cdot \mathrm{Kg}^{-1}\right)\end{array}$ \\
\hline Cassino & $15 / 12 / 94$ & Superfície & 76,2 & 0 & $* 4,559$ & $* 4,559$ & 0,65 & 141,4 \\
\hline Yacht Club & $20 / 12 / 94$ & Superfície & $1.066,9$ & 0,054 & 0,415 & 0,469 & 0,64 & 70,7 \\
\hline $\begin{array}{l}\text { Nascimento } \\
\text { Norte }\end{array}$ & $10 / 01 / 95$ & Superfície & $4.786,7$ & 0,012 & 0,264 & 0,276 & 244,8 & n.t. \\
\hline Feitoria & $20 / 12 / 94$ & Arrasto & 7,5 & 0 & 0 & 0,161 & - & 57,4 \\
\hline Farolete & $20 / 12 / 94$ & Arrasto & 15,0 & 0 & 0,33 & 0,33 & - & n.t. \\
\hline Marambaia & $20 / 12 / 94$ & Arrasto & 16,0 & 0,427 & 0,431 & 0,858 & - & 37,1 \\
\hline Barra & $20 / 12 / 94$ & Arrasto & 41,0 & 0,278 & 0,102 & 1,121 & - & 35,5 \\
\hline \multicolumn{2}{|c|}{ M. aeruginosa $\mathrm{PCC} 7813$} & Cultura & - & 0,512 & 0,008 & 1,145 & - & 70,7 \\
\hline \multicolumn{2}{|c|}{ A. microscopica RSMan 9201} & Cultura & - & 0 & 0 & 0 & - & $1.587,4$ \\
\hline
\end{tabular}

n.t.: não testado; * em $\mu \mathrm{g} . \mathrm{L}^{-1}$ de água filtrada; ** possível variante

de toxinas 2 vezes maior que as células do Nascimento Norte, porém com concentração de toxinas na água até 200 vezes menor.

As concentrações de toxinas nas células ficaram em $11,5 \%$ de MC-LR e $88,5 \%$ da outra variante (possivelmente $\mathrm{MC}-\mathrm{FR}$ ), enquanto foram encontradas, livres na água, $21 \%$ de MC-LR e $79 \%$ da possível MC-FR.

Nos bioensaios com camundongos, observouse uma pequena variação nas toxicidades das amostras das estações fixas do estuário. As estações Feitoria, Marambaia e Barra apresentaram valores de $\mathrm{DL}_{50}-24$ h entre 35 e $57 \mathrm{mg} . \mathrm{Kg}^{-1}$ p.c., enquanto as florações que ocorreram na Praia do Cassino e no Yacht Club tiveram valores relativamente mais altos de $\mathrm{DL}_{50}-24 \mathrm{~h}$, entre 70 e $140 \mathrm{mg} \cdot \mathrm{Kg}^{-1}$ p.c. A cultura de Microcystis aeruginosa PCC7813 apresentou a maior concentração de toxinas por peso de células em relação às florações $\left(1,145 \mu \mathrm{g} \cdot \mathrm{mg}^{-1}\right.$ p.s.) e teve uma $\mathrm{DL}_{50}-24 \mathrm{~h}$ de $70,7 \mathrm{mg} . \mathrm{Kg}^{-1}$ p.c. Outra cultura, Aphanothece microscopica RSMan9201, apresentou $\mathrm{DL}_{50}-24$ h 1.587,4 mg. $\mathrm{Kg}^{-1}$ p.c., sendo utilizada como controle, juntamente com a solução fisiológica.

\section{DISCUSSÃO}

A variação da concentração da clorofila- $a$ foi superior a $10 \mu \mathrm{g} \cdot \mathrm{L}^{-1} \mathrm{em}$ duas ocorrências no estuário da Lagoa dos Patos durante o período estudado. Em setembro, na estação Farolete, foram encontrados valores de até $29 \mu \mathrm{g} . \mathrm{L}^{-1}$. Fortes ventos NE que atuaram nesta região, durante esse período do ano, provocaram a ressuspensão de pellets de M. aeruginosa, depositados por uma grande floração ocorrida em maio de 1994, a qual produziu concentrações de clorofila- $a$ de até $9.000 \mu \mathrm{g} . \mathrm{L}^{-1}$ (Yunes et al., 1994). No verão de 1995, os valores ficaram entre 20 e $30 \mu \mathrm{g} . \mathrm{L}^{-1}$ e esse aumento ocorreu devido, principalmente, à grande abundância de bacillariophyceae nas estações ao norte do estuário e de cyanophyceae próximo ao canal de São Gonçalo, devido à maior descarga de nutrientes nessas regiões, que beneficiaram assim os grupos de água doce. Por outro lado, os menores valores de clorofila- $a$ para o estuário foram encontrados no outono de 1995. Abreu (1987) sugere que os baixos valores de $\mathrm{Cl}-a$ do outono podem estar relacionados com a pressão de pastagem e com o grande volume d'água exportado pelo estuário nessa época.

A maior concentração de colônias de Microcystis aeruginosa foi observada na estação Barra, no mês de dezembro $\left(9.000\right.$ colônias. $\left.\mathrm{L}^{-1}\right)$. Nesse local, a salinidade era de 1,5 , enquanto Feitoria (6.000 colônias. $\left.\mathrm{L}^{-1}\right)$ e Farolete (2.250 colônias. $\mathrm{L}^{-1}$ ) permaneciam com salinidade 0 . Isso evidencia a predominância de massas d'água originárias da Lagoa dos Patos e a influência da água doce no estuário. Os períodos de maior abundância celular (e colonial) de $M$. aeruginosa estão de acordo com as variações de clorofila- $a$ no estuário. 
Outros gêneros de cyanophyceae foram registrados no estuário ao longo do ano. Em agosto, a estação Feitoria apresentou altas concentrações de Anabaena spiroides, indicando a proveniência, desta espécie, da região norte da Lagoa dos Patos, em função da alta pluviosidade naquela época do ano. Na estação Farolete, no entanto, encontraram-se, em setembro, concentrações semelhantes de Merismopedia, uma das cianobactérias mais comuns e abundantes no delta do Guaíba, na região norte da Lagoa dos Patos (Amazarray, 1994). Na estação Torotama foram observadas concentrações de Oscillatoria nos meses de março e julho de 1995. Essa estação é caracterizada por situar-se às margens de uma vila de pescadores, podendo haver contribuições antropogênicas associadas às cargas de nutrientes encontradas nessas águas.

As massas d'água que predominam ao norte do estuário (estação Feitoria e Farolete), devido a semelhanças locais, como profundidade, velocidade de corrente, turbidez e hidrodinâmica (ambas são situadas em zona de canal), apresentaram um comportamento similar nas concentrações celulares microplanctônicas. Essas estações exibiram os maiores picos de diatomáceas, durante o mês de janeiro de 1995, com concentrações entre 9,7.10 e $10,4.10^{5}$ cél. $\mathrm{L}^{-1}$. Na estação Farolete, o ciliado autotrófico Mesodinium rubrum predominou durante os meses de maio e junho, após o desaparecimento de bacillariophyceae. Segundo Abreu (1987), M. rubrum pode dominar com o desaparecimento de Skeletonema costatum devido à forte pressão de pastagem que regula a biomassa dessa diatomácea.

A estação São Gonçalo, devido à singularidade das condições físico-químicas e por possuir origem distinta de nutrientes e organismos, mostrou padrões microplanctônicos diferentes. A estação apresenta água doce durante quase todo o ano. As clorofíceas, junto com diatomáceas de água doce, foram os grupos de maior expressão nessa estação. As cianobactérias da estação São Gonçalo acompanharam o pico das diatomáceas em fevereiro, com, principalmente, A. spiroides, indicando a São Gonçalo como outra fonte desta cianobactéria filamentosa para a região estuarina da Lagoa dos Patos. Nessa mesma época foram observadas florações de $A$. spiroides, que continham MC-LR, na Barragem do Santa Bárbara, próximo ao Canal de São Gonçalo, o qual é res- ponsável pelo abastecimento de água da cidade de Pelotas (Raggett et al., 1996). A toxicidade das florações na Barragem foram determinadas em torno de $400 \mathrm{mg} . \mathrm{Kg}^{-1}$ p.c. (resultados não-publicados).

Densidades celulares muito elevadas, em relação ao mês anterior, são uma característica do crescimento exponencial de uma floração, e conseqüência de condições ambientais ótimas para reprodução. Nos meses de dezembro de 1994 a março de 1995 , a concentração celular média de $M$. aeruginosa, nas 3 estações analisadas, foi de $0,88.10^{6}$ células. $\mathrm{L}^{-1}$, com valores máximos no mês de dezembro de $1,3.10^{6}$ cél. $\mathrm{L}^{-1}$ (estação Feitoria), 1,2.10 $0^{6}$ cél. $\mathrm{L}^{-1}$ (estação Torotama) e 1,4.10 $0^{6}$ cél. L ${ }^{-1}$ (estação Barra). A temperatura elevada e a baixa salinidade do mês de dezembro de 1994, inclusive na estação mais próxima ao oceano, propiciaram condições ótimas para o desenvolvimento, no estuário, de $M$. aeruginosa. A razão ideal de nutrientes nitrogenados (particularmente o nitrato) sobre o fosfato nos meses de novembro e dezembro, bem como os valores de $\mathrm{pH}$, salinidade e temperatura, nessa época (Yunes et al., 1998), sugerem ótimas condições para o crescimento de $M$. aeruginosa e formação de florações.

Em relação à toxicidade das florações de $M$. aeruginosa, na estação de acesso ao estuário (Feitoria), em uma amostragem apenas, obteve-se menor biomassa celular e menor quantidade de microcistinas por peso seco de $M$. aeruginosa em relação às demais estações fixas (Tabela 1). Em contrapartida, a estação mais próxima do Oceano Atlântico (Barra) mostrou os maiores valores de biomassa, a maior quantidade de microcistinas totais e, também, a menor $\mathrm{DL}_{50}-24 \mathrm{~h}$ em camundongos. Segundo Lawton et al. (1994b), concentrações de toxinas acima de $1,0 \mathrm{mg} \cdot \mathrm{g}^{-1}$ p.s. de Microcistinas totais são consideradas altamente tóxicas, assim como valores de toxicidade menores que 100 mg. $\mathrm{Kg}^{-1}$ p.c. para $\mathrm{DL}_{50}-24 \mathrm{~h}$ em camundongos.

Desse modo, os valores das $\mathrm{DL}_{50}-24 \mathrm{~h}$ nas amostras coletadas no estuário da Lagoa dos Patos (57,4 mg. $\mathrm{Kg}^{-1}, 37,1 \mathrm{mg} . \mathrm{Kg}^{-1}$ e $35,5 \mathrm{mg} \cdot \mathrm{Kg}^{-1}$ p.c.) são considerados altamente tóxicos. Valores próximos a estes, de $\mathrm{DL}_{50}-24 \mathrm{~h}$ em camundongos, no mesmo estuário, já haviam sido encontrados por Yunes et al. (1996), em março de 1994, na estação Feitoria (32 mg. $\mathrm{Kg}^{-1}$ p.c.) e, em maio de 1994, em localidade próxima à Barra Falsa $\left(31^{\circ} 49^{\prime} \mathrm{S}\right.$ e $\left.52^{\circ} 13^{\prime} \mathrm{W}\right)\left(59 \mathrm{mg} \cdot \mathrm{Kg}^{-1}\right.$ p.c. $)$. 
Toxicidade semelhante (Bobeda \& Azevedo, 1993) também foi encontrada para Microcystis aeruginosa isolado no Estado do Rio de Janeiro. Esses resultados indicam a alta toxicidade da ocorrência de florações no estuário da Lagoa dos Patos e que estas podem se repetir em periodicidade menor que um ano.

A salinidade parece ter pouca relação com quantidade de toxinas, apesar de, em primeira instância, ser o principal fator de diferença entre as estações dos limites norte e sul do estuário. Embora tenha havido pequena variação de salinidade, no mês de dezembro ( 0 na Feitoria e 1,5 na Barra - dados não apresentados), esta condicionou a diferença de $\mathrm{pH}$ (7,2 na Feitoria e 7,9 na Barra), conferindo melhores condições para o desenvolvimento de florações de Microcystis na estação mais ao sul do estuário.

As concentrações de microcistinas livres encontradas nas águas do estuário da Lagoa dos Patos e Praia do Cassino (estações não-fixas) variaram de $0,65 \mu \mathrm{g} . \mathrm{L}^{-1}$ (Cassino) a 244,8 $\mu \mathrm{g} . \mathrm{L}^{-1}$ (Nascimento Norte). A grande concentração de toxinas nas águas do Nascimento Norte pode ser considerada característica de ambientes em que predominam colônias em todas as fases de crescimento, sob condições ambientais diferentes das anteriores.

A tendência das células de uma floração de M. aeruginosa é a de liberar para o meio as concentrações de toxinas presentes nas células, devido ao envelhecimento das colônias (Codd et al., 1989). As variações nas concentrações de toxinas intracelulares são resultados de condições ambientais, interações com os demais organismos e de diferentes linhagens das Microcystis, podendo, em certas colônias, haver maior produção de toxinas que em outras (Costa \& Azevedo, 1994).

No entanto, a manutenção das condições físico-químicas favoráveis ao desenvolvimento das florações de Microcystis aeruginosa e o alto tempo de retenção da água no estuário, principalmente no período do verão, faz com que estas ocupem as massas d'água estuarinas por mais tempo, podendo refletir na quantidade de toxinas por volume de água.

Uma mesma floração pode produzir diferentes variantes de microcistinas, em diferentes concentrações, as quais podem apresentar toxicidades distintas (Alam et al., 1973). No estuário da Lagoa dos Patos, foram encontradas, no mínimo, 7 variantes da hepatotoxina microcistina, dentre as quais se destacam a MC-LR (com leucina e arginina como os aminoácidos variáveis) e possivelmente a MC-FR (com fenilalanina e arginina).

As maiores concentrações da possível MCFR foram encontradas nas células de amostras da região norte do estuário (estação Farolete e Nascimento Norte), onde existe a predominância de água doce.

Entretanto, a maioria das amostras de toxinas livres identificadas nas águas do estuário compreendeu esta provável MC-FR. Não há evidências bioquímicas para o fato de o transporte de membrana da MC-FR estar associado ao aumento da salinidade.

Porém, dados obtidos por Raggett et al. (1996) para M. aeruginosa PCC7813, uma linhagem isolada de lagos na Escócia, a qual produz as variantes MC-LR e MC-FR em abundância (além de MC-LW e MC-LY), sugerem essa hipótese. Não foi possível identificar as demais variantes das microcistinas encontradas, reforçando a necessidade de continuação dos estudos no estuário e corpo lagunar da Lagoa dos Patos.

As concentrações de toxinas encontradas revelaram um grau elevado para ambientes naturais, estando presentes tanto nas células de Microcystis aeruginosa como livres na água da Lagoa dos Patos.

O acompanhamento das ocorrências de florações de cianobactérias, por meio de monitoramento constante, principalmente no período do verão, torna-se imprescindível para a compreensão dos ciclos de vida e desenvolvimento desses organismos e o seu risco potencial para toda a biota estuarina e, portanto, para as populações locais.

Ao mesmo tempo, análises de água de reservatórios públicos, os quais abastecem cidades, vilas e povoados às margens da Lagoa dos Patos, podem evitar futuros problemas de intoxicações por endotoxinas de cianobactérias e outras algas, mediante o controle do desenvolvimento das florações e utilização de sistemas de tratamento de água adequados.

Hepatotoxicoses, irritações na pele, diarréias, entre outros, são casos já reportados desse tipo de contaminação em populações humanas, além do risco de carcinogênese, devendo ser considerado, portanto, como um problema de saúde pública. 


\section{CONCLUSÕES}

Foi confirmada a presença de colônias de Microcystis aeruginosa, durante os 12 meses estudados, para a região estuarina da Lagoa dos Patos, inclusive para a estação Feitoria, o que indica a região norte da lagoa como principal fonte de entrada dessa espécie para o estuário. A presença de colônias durante, praticamente, todo o ano na desembocadura do estuário (estação Barra), bem como nas áreas rasas (estações Torotama e Marambaia), indica a distribuição de $M$. aeruginosa na superfície d'água de todo o estuário, afetando também a região costeira, inclusive a Praia do Cassino, Oceano Atlântico-Sul.

A elevada abundância de outras espécies do microplâncton, particularmente de diatomáceas, apesar de estas competirem pelos nutrientes do estuário, não evitou a formação e o desenvolvimento de florações de Microcystis aeruginosa no período observado.

As florações de Microcystis aeruginosa que atingiram o estuário se revelaram altamente tóxicas, mediante os testes de toxicidade em camundongos, com $\mathrm{DL}_{50}-24 \mathrm{~h}$ menores que $100 \mathrm{mg} . \mathrm{Kg}^{-1}$ p.c., e concentrações de toxinas nas células que superam $1,0 \mu \mathrm{g} . \mathrm{mg}^{-1}$ p.s. Diversas variantes de microcistinas foram detectadas, com predominância das formas MC-LR e possivelmente MC-FR.

Agradecimentos - $\mathrm{O}$ presente trabalho foi realizado com o apoio do CNPq, FAPERGS, CAPES e Commission of the European Communities.Os autores agradecem aos laboratórios de Fitoplâncton e Hidroquímica Marinha da Universidade do Rio Grande, RS; à Universidade de Dundee, Escócia; aos oceanólogos M. Parise e P. S. Salomon; ao capitão e à tripulação da lancha Larus da Universidade do Rio Grande; e ao funcionário P. Arede pelo imprescindível apoio durante os cruzeiros.

\section{REFERÊNCIAS BIBLIOGRÁFICAS}

ABREU, P. C. O. V., 1987, Variações temporais de biomassa fitoplanctônica (Clorofila-a) e relações com fatores abióticos no canal de acesso ao estuário da Lagoa dos Patos (RS-Brasil). Tese de Mestrado, Universidade do Rio Grande, 107p.

AGUIAR, D. G. \& AZEVEDO, S. M. F. O., 1993, Ocorrência de diferentes cepas tóxicas de Microcystis aeruginosa em diversos corpos d'água brasileiros. $6^{\mathrm{a}}$ Reunião Brasileira de Ficologia, Tramandaí/Imbé, RS.

ALAM, M., IKAWA, M., SASNER, J. J. JR. \& SAWYER, P. J., 1973, Purification of Aphanizomenon flos-aquae toxin and its chemical and physiological properties. Toxicon, 11(1): 65-72.
AMAZARRAY, M. T., 1994, Relatório final do grupo água. Projeto RIOCELL-CENECO (UFRGS), jul/93jun/94, I, II.

ANAGNOSTIDIS, K. \& KOMÁREK, J., 1988, Modern approach to the classification system of cyanophytes, 3 Oscillatoriales. Arch. Hydrobiol. Suppl. 80, 1-4 (Algological Studies, 50-53): 327-472.

AZEVEDO, S. M. F. O., 1996, Toxic cyanobacteria and the Caruaru tragedy. Resumos do IV Simpósio da Soc. Bras. de Toxinol., p. 83, Recife, Pe.

AZEVEDO, S. M. F. O., EVANS, W. R., CARMICHAEL, W. W. \& NAMIKOSHI, M., 1994, First report of microcystins from a brazilian isolate of the cyanobacterium Microcystis aeruginosa. J. Appl. Phycol., 6: 261-265.

BALECH, E., 1988, Los dinoflagelados del Atlantico Sudocidental. Publicaciones Especiales, Instituto Español de Oceanografia, Ministerio de Agricultura, Pesca y Alimentación, 1, 310p.

BARRETO, V., LIRA, V., FIGUEIREDO, J., FITTIPALDI, H., JUCÁ, N., GAYOTTO, I. C., RAPOSO, F., BARBOSA, J., HOLMES, C. E. M., CARDO, D., AZEVEDO, S. M. F. O. \& CARMICHAEL, W. W., 1996, "Caruaru syndrome" a previously undescribed form of acute liver disease in human caused by microcystin with high lethality rate. Resumos do IV Simpósio da Soc. Bras. de Toxinol., p. 88, Recife, PE.

BERGESCH, M., 1990, Variações da biomassa e composição do fitoplâncton na área estuarina rasa da Lagoa dos Patos e suas relações com fatores de influência. Tese de Mestrado, Universidade do Rio Grande, 84p.

BOBEDA, C. R. R. \& AZEVEDO, S. M. F. O., 1993, Análise quali-quantitativa da produção de toxinas em um "bloom" Microcystis aeruginosa no Reservatório do Funil, Município de Resende, RJ. Resumos da 6a Reunião Brasileira de Ficologia, Tramandaí/Imbé, RS.

BOX, J .D., 1981, Enumeration of cell concentrations in suspensions of colonial freshwater microalgae, with particular reference to Microcystis aeruginosa. $\mathrm{Br}$. Phycol. J., 16: 153-164.

CALLIARI, L. J., 1980, Aspectos sedimentológicos e ambientais da região sul da Lagoa dos Patos. Tese de Mestrado, Universidade Federal do Rio Grande do Sul, Instituto de Geociências, 190p.

CARMICHAEL, W. W., 1986, Eutrophication and toxic bluegreen algae waterblooms: their role as agents of waterbased disease. $6^{\text {th }}$ Annual International Symposium Lake and Reservoir Management: influences of nonpoint sources pollutants and acid precipitation, Portland, Oregon.

CARMICHAEL, W. W., 1989, Freshwater cyanobacteria (blue-green algae) toxins. In: C.L. Owsby \& G.V. Odell (eds.), Natural toxins: characterization, pharmacology and therapeutics pergamon press, pp. 3-16.

CASTELlO, J. P., 1978 (coord.), Projeto Lagoa. Relatório do $1^{\circ}$ ao $15^{\circ}$ Cruzeiro, Fundação Universidade do Rio Grande, B. O. A., Sér. Rel., pp. 1-9.

CODD, G. A., BELL, S. G. \& BROOKS, W. P., 1989, Cyanobacterial toxins in water. Wat. Sci. Tech., 21(3): 1-13. 
COSTA, S. M. \& AZEVEDO, S. M. F. O., 1994, Implantação de um banco de cianofíceas tóxicas. Sér. Iheringia, Botânica, 45: 69-72.

DESIKACHARY, T. V., 1959, Cyanophyta. Monographs on algae. Indian Council of Agricultural Research, New Delhi, 686p.

DODGE, J. D., 1985, Atlas of dinoflagellates. Farrand Press, London, 119p.

ELDER, G. H., HUNTER, P. R. \& CODD, G. A., 1993, Hazardous freshwater cyanobacteria (blue-green algae). The Lancet, 341: 1519-1520.

FUJIKI, H., 1992, Is the inhibition of the protein phosphatase 1 and $2 \mathrm{~A}$ activities a general mechanism of tumor promotion in human cancer development? Mol. Carcinog., 5: 9194.

HAMILTON, M. A., RUSSO, R. C. \& THURSTON, R. V., 1977, Trimmed spearman-karber method for estimating median lethal concentrations in toxicity bioassays. Environ. Sci. Technol., 11(7): 714-719. Correction: Environ. Sci. Technol., 12: 417(1978).

KANTIN, R. \& BAUMGARTEN, M. G. Z., 1982, Observações hidrográficas no estuário da Lagoa dos Patos: distribuição e flutuação dos sais nutrientes. Rio Grande, Atlântica, 5: 76-92.

KOMÁREK, J. \& ANAGNOSTIDIS, K., 1986, Modern approach to the classification system of cyanophytes. 2-Chroococcales. Arch. Hydrobiol. Suppl. 73, 2 (Algological Studies, 43): 157-226.

KOMÁREK, J. \& ANAGNOSTIDIS, K., 1989, Modern approach to the classification system of cyanophytes. 2-4Nostocales. Arch. Hydrobiol. Suppl. 82, 3 (Algological Studies, 56): 247-345.

LAWTON, L. A., BEATtie, K. A., HAWSER, S. P., CAMPBELL, D. L. \& CODD, G. A., 1994b, Evaluation of assay methods for the determination of cyanobacterial hepatotoxicity, 111-116. In: G. A. Codd, T. M. Jefferies, C.W. Keevil \& E. Potter (eds.), Detection methods for cyanobacterial toxins, The Royal Soc. Chem., Cambridge, UK

LAWTON, L. A., EDWARDS, C. \& CODD, G. A., 1994a, Extraction and high-performance liquid chromatographic method for the determination of microcystins in raw and treated waters. The Analyst, 119: 1525-1530.

MACKINNEY, G., 1941, Absorption of light by chlorophyll solutions. J. Biol. Chem., 140: 315-322.

MACKINTOSH, C., BEATTIE, K. A., KLUMPP, S., COHEN, P. \& CODD, G. A., 1990, Cyanobacterial microcystin-LR is a potent and specific inhibitor of protein phosphatases 1 and 2A from Both Mammals and Higher Plants. Febs Letters, 264(2): 187-192.

MACKINTOSH, C. \& MACKINTOSH, R. W., 1994, The inhibition of protein phosphatases by toxins: implications for health and an extremely sensitive and rapid bioassay for toxin detection pp. 90-99. In: G. A. Codd, T. M. Jefferies, C. W. Keevil \& E. Potter (eds.), Detection methods for cyanobacterial toxins, The Royal Soc. Chem., Cambridge, UK.
MAEDA, M. \& CAREY, P. G., 1985, An illustrated guide to the species of the family strombiidae (Oligotrichida, Ciliophora). Free Swimming Protozoa Common in the Aquatic Environment, 68p.

MATA, M. M. \& MÖLLER JR., O. O., 1993, Sobre o tempo de descarga do estuário da Lagoa dos Patos, RS, Brasil. Atlântica, 15: 37-48.

NIENCHESKI, L. F. H., BAUMGARTEN, M. G., FILLMAN, G. \& WINDOM, H. L., 1994, Nutrient and suspended matter behavior in the Patos Lagoon Estuary, Brazil. Estuaries of South America. Ed. G. Perillo, Am. Geophys. Union (no prelo).

NIENCHESKI, L. F. \& WINDOM, H. L., 1994, Nutrient flux and budget in Patos Lagoon Estuary. The Sci. Tot. Environ., 149: 53-60.

ODEBRECHT, C., MÖLLER, O. O. JR. \& NIENCHESKI, L. F. H., 1988, Biomassa e categorias de tamanho do fitoplâncton total na Lagoa dos Patos, Rio Grande do Sul, Brasil (verão de 1986). Acta Limnol. Brasil., II: 367-386.

ODEBRECHT, C., SEELIGER, U., COUTINHO, R. \& TORGAN, L. C., 1987, Florações de Microcystis (cianobactérias) na Lagoa dos Patos, RS. Anais do Simpósio sobre Ecossistemas da Costa Sul e Sudeste Brasileira: síntese dos conhecimentos, Cananéia, SP, pp. 280-287.

PAERL, H. W., 1988, Nuisance phytoplankton blooms in coastal, estuarine, and inland waters. Limnol. Oceanogr., 33(4, part 2): $823-847$

PRIDDLE, J. \& FRYXELL, G., 1985, Handbook of the common plankton diatoms of the southern ocean: centrales except the genus Thalassiosira. University Press, Cambridge, Brit. Antart. Surv., 159p.

PROENÇA, L. A. O., 1990, Ciclo anual da produção primária, biomassa do fitoplâncton e carbono orgânico particulado em área rasa da porção sul da Lagoa dos Patos. Tese de Mestrado, Universidade do Rio Grande, 81p.

RAGGETT, S. L., YUNES, J. S., NIENCHESKI, L. F. \& CODD, G. A., 1996, Effects of salinity on the growth and toxicity of Microcystis aeruginosa and ecotoxicological studies on Microcystis blooms in the Patos Lagoon, Brazil. Resumos do "Winter Meeting of the Br. Phycol. Soc”, Lancaster, U.K.

REYNOLDS, C. S. \& JAWORSKI, G. H. M., 1978, Enumeration of natural Microcystis populations. $\mathrm{Br}$. Phycol. J., 13: 269-277.

RICARD, M., 1987, Atlas du phitoplancton marin: diatomophycées. Editions du CNSR, Paris, 297p.

SOURNIA, A., 1986, Atlas du phytoplancton marin: cyanophycées, dictyochophycées, dinophycées, raphidophycées. Editions du CNSR, v. 1, Paris, 219p.

TORGAN, L. C., 1989, Floração de algas: composição, causas e conseqüências. Florianópolis, Ínsula (19): 15-34.

UTERMÖHL, H., 1958, Zur vervollkommung der quantitativen phytoplankton - Methodik. Internationale Vereinigung für Theoretiche und Angewandte Limnologie. Mitteilung, 9, 39p. 
VOLTERRA, L., 1993, Algal toxicity in freshwater environments. In: R. de Bernardi, R. Pagnotta \& A. Pugnetti (eds.), Strategies for lake ecosystems beyond 2000, Mem. Ist. Ital. Idrobiol., 52: 281-299.

YUNES, J. S., NIENCHESKI, L. F. H., SALOMON, P. S., PARISE, M., BEATTIE, K. A., RAGGETT, S. L. \& CODD, G. A., 1994, Development and toxicity of cyanobacteria in the Patos Lagoon Estuary, Southern Brazil. IOC Workshop Report (COI/UNESCO), 101, III, 14-19.

YUNES, J. S., NIENCHESKI, L. F. H., SALOMON, P. S., PARISE, M., BEATTIE, K. A., RAGGETT, S. L. \& CODD, G. A., 1998, The effect of nutrient balance and physical factors on the control of Cyanobacterial blooms in the Patos Lagoon Estuary, Southern Brazil. Verh. Internat. Verein. Limnol., 26: 1796-1800.
YUNES, J. S., SALOMON, P. S., MATTHIENSEN, A., BEATTIE, K. A., RAGGETT, S. L. \& CODD, G. A., 1996, Toxic blooms of cyanobacteria in the Patos Lagoon Estuary, Southern Brazil. J. Aq. Ecos. Health., 5: 223-229.

ZAGATTO, P. A., 1995, Evaluation ecotoxicologique du reservoir Guarapiranga, SP, Bresil, en relation avec le problème des algues toxiques et des algicides. Tese de Doutorado, Université de Metz, France, 86p.

ZAGATTO, P. A. \& ARAGÃO, M. A., 1992, Toxicidade de cianofíceas (algas azuis) do reservatório do Guarapiranga, SP. Resumos do II Encontro de Ecotoxicologia, Cassino, Rio Grande, RS, 55p. 